\title{
A systematic review study of therapeutic effects of Matricaria recuitta chamomile (chamomile)
}

\author{
Sepide Miraj ${ }^{1}$, Samira Alesaeidi ${ }^{2}$
}

\begin{abstract}
${ }^{1}$ M.D., Gynecologist, Fellowship of Infertility, Assistant Professor, Faculty of Medicine, Shahrekord University of Medical Sciences, Shahrekord, Iran

${ }^{2}$ MD, Assistant Professor of Rheumatology and internal medicine, Department of Rheumatology, Internal Medicine, Amiralam Hospital, Tehran University of Medical Sciences, Tehran, Iran
\end{abstract}

\section{Type of article: Systematic review}

\begin{abstract}
Introduction: Matricaria recuitta chamomilla is a plant that grows and is cultivated in some parts of Iran. The aim of this study was to overview the therapeutic effects of this valuable plant. This systematic review was aimed to introduce Matricaria recuitta chamomile, its chemical compounds, and its traditional usages.

Methods: This review article was carried out by searching studies in PubMed, Medline, Web of Science, and IranMedex databases. The initial search strategy identified about 87 references. In this study, 69 studies were accepted for further screening and met all our inclusion criteria [in English, full text, therapeutic effects of Matricaria recuitta chamomilla $L$ and dated mainly from the year 1990 to 2016]. The search terms were "Matricaria recuitta chamomilla L.," "therapeutic properties," "pharmacological effects."

Result: It is commonly used for its antioxidant, antimicrobial, antidepressant, anti-inflammatory, antidiarrheal activities, angiogenesis activity, anticarcinogenic, hepatoprotective, and antidiabetic effects. Besides, it is beneficial for knee osteoarthritis, ulcerative colitis, premenstrual syndrome, and gastrointestinal disorders.

Conclusion: Matricaria recuitta chamomilla L. is widely used for therapeutic and nontherapeutic purposes that trigger its significant value. Various combinations and numerous medicinal properties of its extract, oil, and leaves demand further studies about other useful and unknown properties of this multipurpose plant.

Keywords: Matricaria recuitta chamomilla L., phytochemicals, therapeutic effects, pharmacognosy, alternative and complementary medicine
\end{abstract}

\section{Introduction}

\subsection{Background}

The use of medicinal herbs and herbal medicines is an age-old tradition, and the recent progress in modern therapeutics has stimulated the use of natural products worldwide for diverse ailments and diseases (1-10). Matricaria recutita chamomilla of the Asteraceae family is an annual plant indigenous to Europe and Asia (11), possessing branched, erect, and smooth stems $(12,13)$. Its other names are chamomile or camomile, Italian camomilla, German chamomile, wild chamomile, Hungarian chamomile, (14). German chamomile is useful for treatment of stomachache, irritable bowel syndrome, and insomnia. It possess anti-inflammatory (15-17) and bactericidal, relaxant activities. It also has acaricidal properties. In several animal studies, anxiolytic (18), antimutagenic and cholesterol-lowering, wound healing (19), and antidiabetic properties (20) for this plant were suggested. In in vitro studies, chamomile was demonstrated to possess modest antimicrobial and antioxidant properties (21) and strong antiplatelet and anticarcinoma properties. It is able to cure skin lesions in colostomy patients and is beneficial for generalized anxiety disorders and anxiolytic activity in patients with mild to moderate $\operatorname{GAD}(22,23)$. The chemical compounds of this plant are as follows: apigenin, apigenin-7-O-glucoside, caffeic acid,

\section{Corresponding author:}

Assistant Professor, Dr. Samira Alesaeidi. Department of Rheumatology, internal medicine, Amiralam hospital, Tehran University of Medical Sciences, Tehran, Iran.

Tel: +98.9128884692, Fax:+98.32225456, Email: s-alesaeidi@sina.tums.ac.ir

Received: April 26, Accepted: August 20, 2016, Published: September 2016

iThenticate screening: August 01, 2016, English editing: September 01, 2016, Quality control: September 08, 2016

(C) 2016 The Authors. This is an open access article under the terms of the Creative Commons Attribution-NonCommercialNoDerivs License, which permits use and distribution in any medium, provided the original work is properly cited, the use is non-commercial and no modifications or adaptations are made. 
chlorogenic acid, luteolin, and luteolin-7-O-glucoside, terpene bisabolol (24) farnesene, chamazulene, flavonoids (including apigenin, quercetin, patuletin, and luteolin), and coumarin $(25,26)$.

\subsection{Statement of problem}

In fact, herbal medicines possessing natural essential chemical compounds in their profile could fulfill the primary needs and prerequisites of human beings to cure their diseases $(27,28)$. It has been reported that natural products, their derivatives, and analogs represent over $50 \%$ of all drugs in clinical use, in which natural products derived from higher plants represent about $25 \%$ of the total. The diversity of natural compounds in herbs and their different functions in preventing and treating different diseases, on the one hand, along with their properties of being natural and comfortable with the body and not having adverse effects, providing their proper usage, causes people to be inclined more to their consumption; thus the educated public and health care professionals have enormous interest in concentrating studies on these herbs and diagnosing their therapeutic properties. However, there is a great deal of confusion about their identification, effectiveness, therapeutic dosage, toxicity, standardization, and regulation (29, 30). To achieve this purpose, several studies have been carried out to concentrate on identification of medicinal herbs, thus triggering economically remarkable chances for farmers and related cultivation, harvesting, and agronomic conditions for the ability of the herb to generate favorable chemical and pharmacological profiles (31). Economically, cultivating the Melissa officinalis is cost effective, and, compared with the economic indicators of traditional crops grown on fertilized land, this herb attains much higher profits (32).

\subsection{Objective of research}

This review article is aimed to introduce Matricaria recuitta chamomile, its chemical compounds, and its traditional usages.

\subsection{Research design}

This review article was carried out by searching studies in PubMed, Medline, Web of Science, and IranMedex databases. The initial search strategy identified about 87 references. In this study, 69 studies were accepted for further screening and met all our inclusion criteria [in English, full text, therapeutic effects of Matricaria recuitta chamomilla L and dated mainly from 1990 to 2016. The search terms were "Matricaria recuitta chamomilla L.," "therapeutic properties," "pharmacological effects."

\subsection{Inclusion and exclusion criteria}

Clinical trials, in vitro, in vivo, review articles, or meta-analysis studies were included in this study. Articles were supposed to be in English, their full text should be accessible, and be within the time line of study (from March 1990 to March 2016). For articles associated with other properties of this herb and its antioxidant activities, only their abstracts were available; languages other than English not in the time line of study were excluded from this study.

\subsection{Quality assessment}

To assess the quality of each article, different parts of articles such as the title, abstract, introduction, methods, results, discussion, and conclusion were screened based on a checklist. Eighty-seven articles were identified based on the findings; however, 21 studies were excluded from the review, leaving 56 articles for further analysis.

\section{Results and discussion}

\subsection{Antibacterial activity}

Antibacterial properties of chamomile extract were examined by green synthesis technique; the results showed that chamomile extract (CE) consisted of nanometer structures. Besides, it was found that AgNPs/CE had five times higher antibacterial activity compared with $\mathrm{CE} \operatorname{AgNPs} / \mathrm{G}(33)$. In an in vitro and in vivo study, wound dressings activity of chamomile was evaluated. Inhibitory zone with a diameter of about $7.6 \mathrm{~mm}$ was formed. Results showed that the best samples for wound healing were achieved by mucous tissues formation and not the presence of necrosis and reposition of collagen fibers (34).

\subsection{Antioxidant activity}

The degree of bioactivity of aqueous extracts of this plant was examined. Result showed that microencapsulated extracts of this plant have higher antioxidant activity after the first week (35). The antioxidant properties of chamomile, milk thistle, and halophilic bacteria were investigated. The result was demonstrated that different concentrations of these natural components were able to inhibit upregulation of $\mathrm{H} 2 \mathrm{O} 2$-generated free radicals in human skin fibroblasts in vitro and thus possess antioxidant properties (36). Antioxidant activity of flower extract of 
chamomile was investigated. Besides it was demonstrated that $\mathrm{CuO}$ NPs possesses antioxidant activity in a concentration-dependent manner through breaking the DNA structure (37). Leaf and flowers of feverfew, chamomile, and marigold were compared regarding to their antioxidant activities, and it was found that extracts from flower heads and leaves of chamomile are the richest source of antioxidant activity and among their chemical compounds; bisabolol and chamazulene have the highest antioxidants (38). In an in vitro study, the toxicity of chamomile was examined. The findings demonstrated the accumulation of $\mathrm{Cr}$ and significant abundance in some mineral in roots as well as excess in oxidative stress and discharge of glutathione and (39). In an animal study, the protective effects of extracts of chamomile against reactive oxygen species was investigated. The results suggested that the extracts refrain from producing reactive oxygen species and protecting against hematological parameters; changes in these properties may be due to its antioxidant properties or, on the other hand, resulted from its opposite effect on some intracellular mediators (40). The extract of this plant is able to prevent the production of chemically active species, and it may block lipid peroxidation through various processes.

\subsection{Anti-inflammatory activity}

The anti-inflammatory effect of flavonoid in chamomile was investigated. The anti-inflammatory activity was confirmed by a reduced production of TNF- $\alpha$ seen in mice treated with APG following LPS treatment (41). In a clinical trial study, effects of chamomile on systemic inflammation was examined. Mechanical joint function was improved and pain the knee and lower back was reduced, but no significant anti-inflammatory effects were seen (42). In a clinical trial study, the efficacy of chamomile extracts as mouth rinse was examined, and it showed that the herbal mouth rinses were beneficial, as they have antimicrobial and anti-inflammatory properties (43). As previously mentioned, the compound related to anti-inflammatory effects is apigenin, a flavonoid that is mostly found in its glycosylated form, apigenin-7-glucoside (APG), in natural sources. Acid derivatives are other main compounds involved in this effect.

\subsection{Antidepressive activity}

In a human study, the efficacy of chamomile tea on depression, insomnia and boredom in women following childbirth was evaluated and it was demonstrated that Chamomile tea may be used to reduce depression and improve sleep problems for postpartum women (44).

\subsection{Angiogenesis activity}

The antiangiogenic activity of chamomile extracts was evaluated. Result showed that luteolin and apigenin have the highest capacity in the development of new blood vessels and showed that these compounds are involved in the activity revealed by the methanolic extract (45).

\subsection{Anticarcinogenic activity}

Chamomile, peppermint, and rooibos teabags were tested for their anticancer activity. High levels of dehydro PAs was shown its carcinogenic activity. (46). In an animal study, the artery intimal proliferation after balloon injuries were studied. Anticancer activity of this plant showed through the dynamic expressions of proteins after a balloon injury during intimal proliferation (47).

\subsection{Knee osteoarthritis}

The efficacy and safety of topical chamomile oil in patients with knee osteoarthritis was assessed. It was found that chamomile oil caused increase in the analgesic activity patients with knee osteoarthritis. In addition, their physical function can be improved through topical application of this oil (48). The use of chamomile shows protective effects against mortality in this sample of older adults of Mexican origin for women. Further research is warranted in other populations to determine if these effects are consistent (49).

\subsection{Hepatoprotective effects}

The chemical composition, antioxidant properties, and hepatoprotective effects of subacute pre-treatment with chamomile (Matricaria recutita L.) decoction extract (CDE) against ethanol (EtOH)-induced oxidative stress in rats was assessed, and it was suggested that $\mathrm{CDE}$ exerted a potential hepatoprotective effect against EtOH-induced oxidative stress in rats, at least in part, by negatively regulating Fenton reaction components such as $\mathrm{H}(2) \mathrm{O}(2)$ and free iron, which are known to lead to cytotoxicity mediated by intracellular calcium deregulation (50). 


\subsection{Antimicrobial activity}

Antimicrobial activity of chamomile was assessed, and it showed that chamomile MrBBS incorporate enantiopure ()- $\alpha$-bisabolol as terpene and triggered to produce (-)- $\alpha$-bisabolol (51). Antioxidant properties of chamomile ethanolic extracts were examined. Its antioxidant property was confirmed via presence of high concentration of rosmarinic acid (52). The antibacterial effect of the fractions of chamomile was evaluated against two gram-negative bacteria. Results confirmed its antibacterial effect through its main essential oil components, including coumarin, flavonoids, phenolic acids, and fatty acids (53).

\subsection{Antidiabetic effects}

Efficacy of flower extracts of chamomile for the treatment and prevention of type 2 diabetes was investigated. It demonstrated possessing strong synthetic antidiabetic activity through modulation of PPARs and other factors (54). The anti-obesity activity of chamomile tea was assessed. Chamomile tea demonstrated some beneficial effects on control of blood sugar and fatty acids in patients with type 2 diabetes (55). In an animal study on rats, the antihyperglycemic effects of chamomile tea were investigated, and it was indicated that chamomile tea has a glucose-lowering effect in diabetic rats; thus its daily consumption can be potentially useful in lowering postprandial glucose levels (56).

\subsection{Antidiarrheal activities}

In an animal study, the protective effects of chamomile extract against diarrhea and oxidative stress in rats were investigated. Results showed that extracts of this plant have a strong antidiarrheal and antioxidant properties in rats in a dose-dependent manner against castor oil-induced diarrhea and intestinal fluid accumulation (57).

\subsection{Premenstrual syndrome}

The effects of chamomile extract and mefenamic acid on the severity of symptoms of premenstrual syndrome was compared, and the result showed that consumption of chamomile is more effective than MA in reducing such symptoms (58).

\subsection{Antigastrointestinal disorders}

The clinical efficacy, safety, and tolerability of a licensed herbal combination of myrrh, coffee charcoal, and chamomile extracts in patients with symptoms of acute diarrhea was examined, and it demonstrated that the combination of myrrh, coffee charcoal, and chamomile flower extract is effective, well tolerated, and safe for use in patients with symptoms of acute diarrhea. The effects are comparable with conventional therapies used in routine care (59). Extract of the plant can have a significant role in maintaining health and curing diseases because of its volatile organic compounds and its active constituents such as terpenoids, flavonoids, quercetin, rutin, quercitrin, gallic acid.

\section{Conclusions}

In this study, the therapeutic effects of chamomile were reviewed in detail. The therapeutic effects of Matricaria recuitta chamomile also were reviewed in detail. The findings of this study indicated that this plant is commonly used for its antioxidant, antimicrobial, antidepression, anti-inflammatory, antidiarrheal and angiogenesis activity, anticarcinogenic, hepatoprotective, and antidiabetic effects. Besides, it is beneficial for knee osteoarthritis, ulcerative colitis, premenstrual syndrome, and gastrointestinal disorders. Antimicrobial activity (antiparasitic, antibacterial, antiviral properties) was reported. Many studies confirmed the antioxidative effects of this plant; finally, more complementary studies in different therapeutic effects of this herb in clinical trial studies may be appropriate for future studies.

Acknowledgments:

We appreciate the Research and Technology Deputy of Shahrekord University of Medical Sciences for its technical and financial support.

\section{Conflict of Interest:}

There is no conflict of interest to be declared.

\section{Authors' contributions:}

Both authors contributed to this project and article equally. Both authors read and approved the final manuscript. 


\section{References:}

1) Miraj S, Azizi N, Kiani S. A review of chemical components and pharmacological effects of Melissa officinalis L. Der Pharmacia Lettre. 2016; 8(6): 229-37.

2) Miraj S, Kiani S. Study of pharmacological effect of Ocimum basilicum: A review. Der Pharmacia Lettre. 2016; 8(9): 276-80.

3) Miraj S, Kiani S. Astragalus membranaceus: A review study of its anti-carcinoma activities. Der Pharmacia Lettre. 2016; 8(6): 59-65.

4) Miraj S, Kiani S. Study of pharmacological effect of Avena sativa: A review. Der Pharmacia Lettre. 2016, 8(9): 137-40.

5) Miraj S, Kiani S. Study of pharmacological effect of Mentha pulegium: A review. Der Pharmacia Lettre. 2016; 8(9): 242-5.

6) Miraj S, Kiani S. Bioactivity of Sesamum indicum: A review study. Der Pharmacia Lettre. 2016; 8(6): 32834.

7) Miraj S, Kiani S. Study of therapeutic effects of Cynara scolymus L.: A review. Der Pharmacia Lettre. 2016; 8(9): 168-73.

8) Masoudi M, Rafieian Kopaei M, Miraj S. A comparison of the efficacy of metronidazole vaginal gel and Myrtus (Myrtus communis) extract combination and metronidazole vaginal gel alone in the treatment of recurrent bacterial vaginosis. Avicenna J Phytomed. 2016; 6(6): 1-7.

9) kaveh Baghbahadorani F, Miraj S. The impact of Silymarin on improvement of platelet abnormalities in patients with severe preeclampsia. Electron Physician. 2016; 8(5): 2436. doi: 10.19082/2436.

10) Masoudi M, Miraj S, Rafieian-Kopaei M. Comparison of the Effects of Myrtus Communis L, Berberis Vulgaris and Metronidazole Vaginal Gel alone for the Treatment of Bacterial Vaginosis. J clin diag res. 2016; 10(3): 4-7. doi: 10.7860/JCDR/2016/17211.7392. PMID: 27134945, PMCID: PMC4843330.

11) Ortiz MI, Fernández-Martínez E, Soria-Jasso LE, Lucas-Gómez I, Villagómez-Ibarra R, González-García MP, et al. Isolation, identification and molecular docking as cyclooxygenase (COX) inhibitors of the main constituents of Matricaria chamomilla L. extract and its synergistic interaction with diclofenac on nociception and gastric damage in rats. Biomed Pharmacother. 2016; 78: 248-56. doi: 10.1016/j.biopha.2016.01.029. PMID: 26898449.

12) McKay DL, Blumberg JB. A review of the bioactivity and potential health benefits of chamomile tea (Matricaria recutita L.). Phytother Res. 2006; 20(7): 519-30. PMID: 16628544.

13) Morales-Bozo I, Ortega-Pinto A, Rojas Alcayaga G, Aitken Saavedra JP, Salinas Flores O, Lefimil Puente $\mathrm{C}$, et al. Evaluation of the effectiveness of a chamomile (Matricaria chamomilla) and linseed (Linum usitatissimum) saliva substitute in the relief of xerostomia in elders. Gerodontology. 2016. doi: 10.1111/ger.12220. PMID: 26763612.

14) Mekonnen A, Yitayew B, Tesema A, Taddese S. In Vitro Antimicrobial Activity of Essential Oil of Thymus schimperi, Matricaria chamomilla, Eucalyptus globulus, and Rosmarinus officinalis. Int J Microbiol. 2016; 2016: 8. doi: 10.1155/2016/9545693.

15) Zargaran A, Borhani-Haghighi A, Faridi P, Daneshamouz S, Kordafshari G, Mohagheghzadeh A. Potential effect and mechanism of action of topical chamomile (Matricaria chammomila L.) oil on migraine headache: A medical hypothesis. Med Hypotheses. 2014; 83(5): 566-9. doi: 10.1016/j.mehy.2014.08.023.

16) Srivastava JK, Pandey M, Gupta S. Chamomile, a novel and selective COX-2 inhibitor with antiinflammatory activity. Life Sci. 2009; 85(19-20): 663-9. doi: 10.1016/j.lfs.2009.09.007. PMID: 19788894, PMCID: PMC2784024.

17) Sharifi H, Minaie MB, Qasemzadeh MJ, Ataei N, Gharehbeglou M, Heydari M. Topical use of Matricaria recutita L (Chamomile) Oil in the Treatment of Monosymptomatic Enuresis in Children: A Double-Blind Randomized Controlled Trial. J Evid Based Complementary Altern Med. 2015; pii: 2156587215608989. PMID: 26427789.

18) Amsterdam JD, Shults J, Soeller I, Mao JJ, Rockwell K, Newberg AB. Chamomile (Matricaria recutita) may provide antidepressant activity in anxious, depressed humans: an exploratory study. Altern Ther Health Med. 2012; 18(5): 44-9. PMID: 22894890, PMCID: PMC3600408.

19) Hashempur MH, Lari ZN, Ghoreishi PS, Daneshfard B, Ghasemi MS, Homayouni K, et al. A pilot randomized double-blind placebo-controlled trial on topical chamomile (Matricaria chamomilla L.) oil for severe carpal tunnel syndrome. Complement Ther Clin Pract. 2015; 21(4): 223-8. doi: 10.1016/j.ctcp.2015.08.001. PMID: 26573447. 
20) Jarrahi M, Vafaei AA, Taherian AA, Miladi H, Rashidi Pour A. Evaluation of topical Matricaria chamomilla extract activity on linear incisional wound healing in albino rats. Nat Prod Res. 2010; 24(8): 697-702. doi: 10.1080/14786410701654875. PMID: 20432150.

21) Satyal P, Shrestha S, Setzer WN. Composition and Bioactivities of an (E)-beta-Farnesene Chemotype of Chamomile (Matricaria chamomilla) Essential Oil from Nepal. Nat Prod Commun. 2015; 10(8): 1453-7. PMID: 26434140.

22) Amsterdam JD, Li Y, Soeller I, Rockwell K, Mao JJ, Shults J. A randomized, double-blind, placebocontrolled trial of oral Matricaria recutita (chamomile) extract therapy for generalized anxiety disorder. J Clin Psychopharmacol. 2009; 29(4): 378-82. doi: 10.1097/JCP.0b013e3181ac935c. PMID: 19593179, PMCID: PMC3600416.

23) Pelissolo A. [Efficacy and tolerability of escitalopram in anxiety disorders: a review]. Encephale. 2008; 34(4): 400-8. doi: 10.1016/j.encep.2008.04.004. PMID: 18922243.

24) Gosztola B, Sarosi S, Nemeth E. Variability of the essential oil content and composition of chamomile (Matricaria recutita L.) affected by weather conditions. Nat Prod Commun. 2010; 5(3): 465-70. PMID: 20420329.

25) Orav A, Raal A, Arak E. Content and composition of the essential oil of Chamomilla recutita (L.) Rauschert from some European countries. Nat Prod Res. 2010; 24(1): 48-55. doi: 10.1080/14786410802560690. PMID: 20013472.

26) Avonto C, Wang M, Chittiboyina AG, Avula B, Zhao J, Khan IA. Hydroxylated bisabolol oxides: evidence for secondary oxidative metabolism in Matricaria chamomilla. J Nat Prod. 2013; 76(10): 1848-53. doi: 10.1021/np4003349. PMID: 24070008.

27) Kamboj VP. Herbal medicine. CURRENT SCIENCE-BANGALORE. 2000; 78(1): 35-8.

28) Miraj S, Kiani S. A review study of therapeutic effects of Iranian borage (Echium amoenum Fisch). Der Pharmacia Lettre. 2016; 8(6): 102-9.

29) Miraj S, Jivad N, Kiani S. A review of chemical components and pharmacological effects of Kelussia odoratissima Mozaff. Der Pharmacia Lettre. 2016; 8(1): 140-7.

30) Miraj S, Rafiean M, Kiani S. Melissa officinalis L: a systematic review with antioxidant prospective. Journal of Evidence-Based Complementary and Alternative Medicine. doi: 10.1177/2156587216663433

31) Miraj S, Rafiean M, Kiani S. The association between dystemprement and prevention of diseases:a systematic review, j clinic diag res. 2016; 10(9): YE01-YE06, DOI: 10.7860/JCDR/2016/19023.8511

32) Miller LG. Herbal medicinals: selected clinical considerations focusing on known or potential drug-herb interactions. Arch Intern Med. 1998; 158(20): 2200-11. PMID: 9818800.

33) Parlinska-Wojtan M, Kus-Liskiewicz M, Depciuch J, Sadik O. Green synthesis and antibacterial effects of aqueous colloidal solutions of silver nanoparticles using camomile terpenoids as a combined reducing and capping agent. Bioprocess Biosyst Eng. 2016; 39(8): 1213-23. doi: 10.1007/s00449-016-1599-4. PMID: 27083587, PMCID: PMC4945692.

34) Motealleh B, Zahedi P, Rezaeian I, Moghimi M, Abdolghaffari AH, Zarandi MA. Morphology, drug release, antibacterial, cell proliferation, and histology studies of chamomile-loaded wound dressing mats based on electrospun nanofibrous poly(varepsilon-caprolactone)/polystyrene blends. J Biomed Mater Res B Appl Biomater. 2014; 102(5): 977-87. doi: 10.1002/jbm.b.33078. PMID: 24259351.

35) Caleja C, Ribeiro A, Barros L, Barreira JC, Antonio AL, Beatriz PPOM, et al. Cottage cheeses functionalized with fennel and chamomile extracts: Comparative performance between free and microencapsulated forms. Food chem. 2016; 199: 720-6. doi: 10.1016/j.foodchem.2015.12.085. PMID: 26776029.

36) Mamalis A, Nguyen DH, Brody N, Jagdeo J. The active natural anti-oxidant properties of chamomile, milk thistle, and halophilic bacterial components in human skin in vitro. J Drugs Dermatol. 2013; 12(7): 780-4. PMID: 23884490.

37) Duman F, Ocsoy I, Kup FO. Chamomile flower extract-directed $\mathrm{CuO}$ nanoparticle formation for its antioxidant and DNA cleavage properties. Mater Sci Eng C Mater Biol Appl. 2016; 60: 333-8. doi: 10.1016/j.msec.2015.11.052. PMID: 26706538.

38) Agatonovic-Kustrin S, Babazadeh Ortakand D, Morton DW, Yusof AP. Rapid evaluation and comparison of natural products and antioxidant activity in calendula, feverfew, and German chamomile extracts. J Chromatogr A. 2015; 1385: 103-10. doi: 10.1016/j.chroma.2015.01.067. PMID: 25666499.

39) Kovacik J, Babula P, Hedbavny J, Klejdus B. Hexavalent chromium damages chamomile plants by alteration of antioxidants and its uptake is prevented by calcium. J Hazard Mater. 2014; 273: 110-7. doi: 10.1016/j.jhazmat.2014.03.040. PMID: 24727012. 
40) Jabri MA, Sani M, Rtibi K, Marzouki L, El-Benna J, Sakly M, et al. Chamomile decoction extract inhibits human neutrophils ROS production and attenuates alcohol-induced haematological parameters changes and erythrocytes oxidative stress in rat. Lipids Health Dis. 2016; 15(1): 65. doi: 10.1186/s12944-016-0233-4. PMID: 27029534, PMCID: PMC4815212.

41) Miguel FG, Cavalheiro AH, Spinola NF, Ribeiro DL, Barcelos GR, Antunes LM, et al. Validation of a RPHPLC-DAD Method for Chamomile (Matricaria recutita) Preparations and Assessment of the Marker, Apigenin-7-glucoside, Safety and Anti-Inflammatory Effect. Evid Based Complement Alternat Med. 2015; 2015: 9. doi: 10.1155/2015/828437.

42) Drummond EM, Harbourne N, Marete E, Jacquier JC, O'Riordan D, Gibney ER. An in vivo study examining the antiinflammatory effects of chamomile, meadowsweet, and willow bark in a novel functional beverage. J Diet Suppl. 2013; 10(4): 370-80. doi: 10.3109/19390211.2013.830680. PMID: 24237191.

43) Batista AL, Lins RD, de Souza Coelho R, do Nascimento Barbosa D, Moura Belem N, Alves Celestino FJ. Clinical efficacy analysis of the mouth rinsing with pomegranate and chamomile plant extracts in the gingival bleeding reduction. Complement Ther Clin Pract. 2014; 20(1): 93-8. doi: 10.1016/j.ctcp.2013.08.002. PMID: 24439653.

44) Chang SM, Chen $\mathrm{CH}$. Effects of an intervention with drinking chamomile tea on sleep quality and depression in sleep disturbed postnatal women: a randomized controlled trial. J Adv Nurs. 2016; 72(2): 306-15. doi: 10.1111/jan.12836. PMID: 26483209.

45) Guimaraes R, Calhelha RC, Froufe HJ, Abreu RM, Carvalho AM, Queiroz MJ, et al. Wild Roman chamomile extracts and phenolic compounds: enzymatic assays and molecular modelling studies with VEGFR-2 tyrosine kinase. Food Funct. 2016; 7(1): 79-83. doi: 10.1039/c5fo00586h. PMID: 26446815.

46) Shimshoni JA, Duebecke A, Mulder PP, Cuneah O, Barel S. Pyrrolizidine and tropane alkaloids in teas and the herbal teas peppermint, rooibos and chamomile in the Israeli market. Food Addit Contam Part A Chem Anal Control Expo Risk Assess. 2015; 32(12): 2058-67. doi: 10.1080/19440049.2015.1087651. PMID: 26365752.

47) Huang Z, Li Y, Niu L, Xiao Y, Pu X, Zheng H, et al. Dynamic expressions of monocyte chemo attractant protein-1 and $\mathrm{CC}$ chamomile receptor 2 after balloon injury and their effects in intimal proliferation. Biomed Eng Online. 2015; 14: 55. doi: 10.1186/s12938-015-0030-8. PMID: 26062549, PMCID: PMC4469411.

48) Shoara R, Hashempur MH, Ashraf A, Salehi A, Dehshahri S, Habibagahi Z. Efficacy and safety of topical Matricaria chamomilla L. (chamomile) oil for knee osteoarthritis: A randomized controlled clinical trial.Complement Ther Clin Pract. 2015; 21(3): 181-7. doi: 10.1016/j.ctcp.2015.06.003. PMID: 26256137.

49) Howrey BT, Peek MK, McKee JM, Raji MA, Ottenbacher KJ, Markides KS. Chamomile Consumption and Mortality: A Prospective Study of Mexican Origin Older Adults. Gerontologist. 2015; pii: gnv051. PMID: 26035879.

50) Sebai H, Jabri MA, Souli A, Hosni K, Rtibi K, Tebourbi O, et al. Chemical composition, antioxidant properties and hepatoprotective effects of chamomile (Matricaria recutita L.) decoction extract against alcohol-induced oxidative stress in rat. Gen Physiol Biophys. 2015; 34(3): 263-75. doi: 10.4149/gpb2014039. PMID: 25816359.

51) Son YJ, Kwon M, Ro DK, Kim SU. Enantioselective microbial synthesis of the indigenous natural product (-)-alpha-bisabolol by a sesquiterpene synthase from chamomile (Matricaria recutita). Biochem J. 2014; 463(2): 239-48. doi: 10.1042/BJ20140306. PMID: 25048207.

52) Mekinic IG, Skroza D, Ljubenkov I, Krstulovic L, Mozina SS, Katalinic V. Phenolic acids profile, antioxidant and antibacterial activity of chamomile, common yarrow and immortelle (Asteraceae). Nat Prod Commun. 2014; 9(12): 1745-8. PMID: 25632475.

53) Moricz AM, Ott PG, Alberti A, Boszormenyi A, Lemberkovics E, Szoke E, et al. Applicability of preparative overpressured layer chromatography and direct bioautography in search of antibacterial chamomile compounds. J AOAC Int. 2013; 96(6): 1214-21. doi: 10.5740/jaoacint.SGEMoricz. PMID: 24645496.

54) Weidner C, Wowro SJ, Rousseau M, Freiwald A, Kodelja V, Abdel-Aziz H, et al. Antidiabetic effects of chamomile flowers extract in obese mice through transcriptional stimulation of nutrient sensors of the peroxisome proliferator-activated receptor (PPAR) family. PloS one. 2013; 8(11): 80335. doi: 10.1371/journal.pone.0080335. PMID: 24265809, PMCID: PMC3827197. 
55) Rafraf M, Zemestani M, Asghari-Jafarabadi M. Effectiveness of chamomile tea on glycemic control and serum lipid profile in patients with type 2 diabetes. J Endocrinol Invest. 2015; 38(2): 163-70. doi: 10.1007/s40618-014-0170-x. PMID: 25194428.

56) Khan SS, Najam R, Anser H, Riaz B, Alam N. Chamomile tea: herbal hypoglycemic alternative for conventional medicine. Pak J Pharm Sci. 2014; 27 (5 Spec no): 1509-14. PMID: 25176245.

57) Sebai H, Jabri MA, Souli A, Rtibi K, Selmi S, Tebourbi O, et al. Antidiarrheal and antioxidant activities of chamomile (Matricaria recutita L.) decoction extract in rats. J Ethnopharmacol. 2014; 152(2): 327-32. doi: 10.1016/j.jep.2014.01.015. PMID: 24463157.

58) Sharifi F, Simbar M, Mojab F, Majd HA. Comparison of the effects of Matricaria chamomila (Chamomile) extract and mefenamic acid on the intensity of premenstrual syndrome. Complement Ther Clin Pract. 2014; 20(1): 81-8. doi: 10.1016/j.ctcp.2013.09.002. PMID: 24439651.

59) Albrecht U, Muller V, Schneider B, Stange R. Efficacy and safety of a herbal medicinal product containing myrrh, chamomile and coffee charcoal for the treatment of gastrointestinal disorders: a non-interventional study. BMJ Open Gastroenterol. 2014; 1(1): e000015. doi: 10.1136/bmjgast-2014-000015. 